\title{
GAMBARAN PERSEPSI MASYARAKAT TENTANG STIGMATISASI BAGI ODHA DI RSUD MGR. GABRIEL MANEK SVD ATAMBUA
}

\author{
Wendelina Bubu*) \\ Pius A. L. Berek*) \\ Yusfina M. Rua*) \\ *) Program Studi Keperawatan Universitas Timor Kampus Atambua, Jl. Wehor Kabuna Haliwen Atambua Nusa \\ Tenggara Timur. Post: 85711. Email: francis_domin2012@yahoo.com. Phone: 081280426042
}

\begin{abstract}
ABSTRAK
Permasalahan HIV / AIDS sejak lama menjadi isu bersama yang terus menyedot perhatian berbagai kalangan diseluruh dunia, terutama sektor kesehatan. HIV / AIDS merupakan masalah global yang melanda dunia sejak awal dekade 80 - an. Begitu banyak isu legal yang terjadi dalam perawatan pasien, salah satunya adalah perawatan pasien HIV / AIDS yang menimbulkan banyak masalah mengenai stigma. Salah satu kendala dalam pengendalian penyakit HIV / AIDS adalah mengenai stigma negatif terhadap penderita HIV / AIDS. Stigma terkait HIV / AIDS adalah bentuk prasangka buruk yang mendiskreditkan atau menolak seseorang atau kelompok karena mereka dianggap berbeda dengan diri kita atau kebanyakan orang. Tujuan dari penelitian ini untuk mengetahui mengenai gambaran persepsi masyarakat tentang stigmatisasi bagi ODHA di RSUD Mgr. Gabriel Manek, SVD Atambua. Penelitian ini merupakan penelitian yang menggunakan analisis univariat yaitu menganalisis terhadap tiap variabel dari hasil penelitian. Sampel yang digunakan adalah 177 responden. Hasil penelitian menunjukan bahwa terdapat 48,82 \% responden yang memberikan stigma negatif kepada ODHA dan terdapat $51,18 \%$ masyarakat tidak memberikan stigma kepada ODHA. Setiap variabel yang diteliti yaitu jenis kelamin, umur, pendidikan, pekerjaan, saling berpengaruh satu dengan yang lain sehingga menyebabkan munculnya stigma kepada ODHA. Hubungan yang signifikan dari setiap variabel yang diteliti saling berpengaruh, sehingga peneliti menyarankan agar pendidikan dan promosi kesehatan mengenai HIV / AIDS terus dilakukan diberbagai kalangan, untuk meningkatkan pengetahuan dan menambah wawasan bagi masyarakat.
\end{abstract}

Kata Kunci: HIV/AIDS, Stigma, ODHA, Masyarakat.

\section{DESCRIPTION OF COMMUNITY PERCEPTIONS ABOUT STIGMATIZATION FOR PLWHA IN MGR. GABRIEL MANEK SVD, ATAMBUA HOSPITAL}

\author{
Wendelina Bubu*) \\ Pius A. L. Berek*) \\ Yusfina M. Rua*) \\ *) Nursing Program at University of Timor Atambua Campus, Jl. Wehor Kabuna Haliwen Atambua East Nusa \\ Tenggara Post: 85711. Email: francis_domin2012@yahoo.com. Phone: 081280426042
}

\section{ABSTRACT}

The problem of HIV / AIDS has long been a shared issue that continues to attract the attention of various groups around the world, especially the health sector. HIV / AIDS is a global problem that has hit the world since the early 1980. Where so many legal issues occur in patient care, one of which is the care of patients with HIV / AIDS which raises many problems regarding stigma. One of the obstacles in controlling HIV / AIDS is the negative stigma towards people with HIV / AIDS. Stigma related to HIV / AIDS is a form of prejudice that discredits or rejects someone or group because they are considered different from ourselves or most people. The purpose of this study was to find out the description of the community's perception of stigmatization for PLWHA in the Hospital of Mgr. Gabriel Manek, SVD Atambua. This study is a study that uses univariate analysis, namely analyzing each variable from the results of each study. And the sample used was 177 respondents. The results of this study show that there are $48.82 \%$ of the community, which gives a negative stigma to PLWHA and there are 51.18\% of the community does not give stigma to PLWHA. Each variable studied, namely gender, age, education, occupation, influences each other, causing stigma to PLWHA. Significant relationship of each variable studied influences each other, so researchers suggest that education and health promotion on HIV / AIDS continue to be carried out in various circles, to increase knowledge and add insight to the community. 


\section{PENDAHULUAN}

HIV atau Human

Immunodeficiency Virus merupakan virus yang melemahkan sistem kekebalan tubuh manusia. AIDS adalah singkatan dari Acquired Immuno Deficiency Syndrome, yang merupakan sekumpulan gejala penyakit yang disebabkan oleh penurunan sistem kekebalan tubuh karena serangan HIV (Djuanda, 2007 dalam Febrianti 2017 ). Permasalahan HIV / AIDS sejak lama menjadi isu bersama yang terus menyedot perhatian berbagai kalangan diseluruh dunia, terutama sektor kesehatan. HIV / AIDS merupakan masalah global yang melanda dunia sejak awal dekade 80-an,

( BKKBN , 2014 ). Begitu banyak isu legal yang terjadi dalam perawatan pasien. Perawatan pasien dengan HIV / AIDS menimbulkan banyak masalah sulit, salah satunya adalah mengenai stigma terhadap penderita HIV / AIDS yang biasa disebut sebagai Orang Dengan HIV/AIDS (ODHA). Stigma adalah prasangka memberikan label sosial yang bertujuan untuk memisahkan atau mendiskreditkan seseorang atau sekelompok orang dengan cap atau pandangan buruk. Salah satu kendala dalam pengendalian penyakit HIV / AIDS adalah mengenai stigma negatif terhadap penderita HIV / AIDS (ODHA). Stigma adalah bentuk prasangka yang mendiskreditkan atau menolak seseorang atau kelompok karena mereka dianggap berbeda dengan diri kita atau kebanyakan orang,(Ardhiyanti,2015). Stigma terkait HIV/AIDS adalah segala prasangka, penghinaan dan diskriminasi yang ditujukan kepada ODHA serta individu, kelompok atau komunitas yang berhubungan dengan ODHA tersebut.

Menurut UNAIDS (2006), kasus HIV / AIDS didunia mencapai 39,4 juta orang, kelompok dewasa sebanyak 37,2 juta orang, dan anak - anak dibawah usia 15 tahun sebanyak 2,3 juta orang (KemenkesRI, 2007 dalam Hati 2017). Di Asia terutama di Filipina kasus infeksi HIV / AIDS sangat mengkhwatirkan karena terjadi peningkatan. Akhir tahun 2016 sekitar 10.500 warga Filipina terinfeksi HIV. Sedangkan berdasarkan hasil laporan dari Kementerian Kesehatan Republik Indonesia bulan Juni 2015, adanya kecenderungan peningkatan jumlah kasus HIV dari tahun ke tahun. Pada tahun 2013 pengidap HIV sebanyak 29.037, dan AIDS sebanyak 10.163; pada tahun 2014 pengidap HIV sebanyak 32.711, AIDS sebanyak 5.494 dan pada tahun 2015 pengidap HIVsebanyak 17.325 dan sebanyak AIDS 1.238 kasus (Kemenkes RI,2015, dalam Febrianti 2017). Di NTT kasus kumulatif HIV/AIDS sampai dengan bulan Desember 2012 sebesar 1918 kasus, HIV positif terjaring sebesar 837 kasus dan AIDS sebesar 1081 kasus, yang meninggal sebesar 443 kasus dan 8 kasus diantaranya ditolak oleh keluarga ( KPAD NTT,2013 \& KPAD Manggarai, 2013 ). Menurut KPAN 2011, kasus AIDS Indonesia Januari sampai September 2011 sebesar 1805 kasus. Secara komulatif sampai dengan Juli 2011 sebesar 26.483. Terdapat $45,9 \% \quad$ usia $20-29$ tahun (BKKBN.RI,2012). Survei Asia Pasific Network (APN) PLWHI, Juli tahun 2001 dan Nevember 2002 menggambarkan $80 \%$ responden melaporkan adanya stigma dan diskriminatif dimasyarakat (KPAN,2011).

Menurut Fredericson dan Kanabus (2007), sejak pertama kali ditemukan penyakit HIV/AIDS didunia sekitar tahun 1981,berbagai respon seperti ketakutan, penolakan, stigma dan diskriminasi telah muncul bersamaan dengan terjadinya epidemik. Stigma digambarkan sebagai cap buruk yang sangat memojokan seseorang dimata orang lain. Stigma tentang HIV/AIDS telah tersebar secara cepat, menyebabkan terjadinya kecemasan dan prasangka negatif terhadap orang dengan HIV/AIDS (ODHA). ODHA adalah sebutan bagi orang yang telah positif HIV dan AIDS. Dengan status sebagai ODHA banyak diantara penderita yang mengucilkan diri sendiri. Sikap dan pandangan masyarakat terhadap ODHA sangat buruk sehingga melahirkan 
permasalahan serta tindakan pelanggaran Hak Asasi Manusia (HAM) bagi penderita dengan HIV/AIDS dan keluarganya. (Fauk et al., 2018) dalam penelitiannya menemukan bahwa orang merasa enggan untuk menjalani tes HIV dan keseriusan yang dirasakan infeksi HIV.

Stigma pada ODHA menghambat proses sosialisasi, bahkan dalam hal pengobatan penderita tersebut. Akibat dari stigma ODHA sering didiskriminasi dan cenderung dikucilkan oleh keluarga, teman-teman disekitar lingkungan tersebut. Pada sisi lain mereka juga mengalami diskriminasi dalam pelayanan kesehatan, pendidikan dan hak-hak lainnya. Lebih lanjut, stigma mempengaruhi kehidupan ODHA dengan menimbulkan depresi dan kecemasan, rasa sedih, rasa bersalah, dan perasaan kurang bernilai. Selain itu stigma menurunkan kualitas hidup, membatasi akses penggunaan layanan kesehatan, dan mengurangi kepatuhan terhadap antiretroviral (Ardani \& Handayani, 2017). Selanjunya menurut Eka, (2012) stigma juga menyebabkan ODHA tidak ingin berkonsultasi, menolak mendapatkan pelayanan kesehatan serta takut untuk membuka status. Dibeberapa Kabupaten penderita HIV/AIDS mendapatkan obat dikabupaten lain karena alasan malu dengan keluarga dan masyarakat disekitar. Sikap stigma manyarakat terhadap HIV/AIDS sudah muncul sejak adanya penderita HIV / AIDS asal Adonara tahun1997. Ketika penderita tersebut datang dari Malaysia, keluarganya menjadi malu karena ada rekomendasi bahwa sakit yang diderita adalah HIV/AIDS. Keluarga dan masyarakat disekitar mengisolasinya sampai penderita itu meninggal (Hati, 2017).

Untuk itu pengetahuan dan informasi yang benar mengenai HIV/AIDS perlu ditingkatkan,dan perlu digalakan upaya penghilangan stigma terhadap ODHAdari berbagai elemen yang memiliki keterkaitan dengan para penderita HIV/AIDS. Dukungan dan kerja sama dari berbagai elemen dapat mengurangi adanya stigma terhadap ODHA dan memberi motivasi bagi ODHA untuk mengikuti prosedur pengobatan antiretroviral.

\section{METODOLOGO}

Penelitian ini merupakan penelitian kuantitatif deskriptif dengan pendekatan cross sectiona untuk mengetahui gambaran persepsi masyarakat tentang stigmatisasi bagi ODHA di RSUD MGR Gabriel Manek SVD Atambua.

Populasi dalam penelitian ini adalah semua orang yang berkunjung ke RSUD MGR Gabriel Manek SVD Atambua. Dengan menggunakan accidental sampling diperoleh responden sebesar 170 orang, dengan kriteria inklusi: Bersedia menjadi responden; Pengunjung diRSUD MGR Gabriel Manek SVD Atambua; dan Pengunjung yang bisa baca dan tulis. Peneliti menggunakan kuisioner untuk mengumpulan data. Analisa data menggunakan univariat untuk mengidentifikasi setiap data hasil penelitian.

\section{HASIL PENELITIAN}

\section{a. Gambaran Lokasi Penelitian.}

Lokasi penelitian ini dilakukan di Rumah Sakit Umum Daerah Mgr. Gabriel Manek SVD, Atambua. Rumah Sakit Umum Daerah Mgr. Gabriel Manek SVD Atambua adalah salah satu Lembaga Teknis Daerah Kabupaten Belu yang dibentuk berdasarkan Perda sebagai salah satu Rumah Sakit milik Pemerintah Daerah Kabupaten Belu yang terletak ditengah kota Atambua yang beralamat pada Jl. DR. Soetomo No. 2. Atambua. RSUD Mgr. Gabriel Manek SVD Atambua menjadi rumah sakit rujukan di Kota Atambua yang berkewajiban memberi pelayanan kepada seluruh lapisan masyarakat.

Sebagai salah satu instansi kesehatan Pemerintah Daerah, RSUD Mgr. Gabriel Manek SVD Atambua bertanggung jawab melaksanakan upaya kuratif dan rehabilitative disamping upaya promotif dan preventif. Disamping itu rumah sakit adalah suatu tempat bermuaranya segala dampak pada manusia dan lingkungan. Dalam hal ini rumah sakit adalah suatu perekam yang baik menyangkut apa 
yang terjadi di daerah - daerah dimana terdapat rumah sakit dan berkewajiban untuk bersama instansi kesehatan daerah lain secara aktif melakukan upaya - upaya secara lintas program atau sektoral dalam menanggulangi permasalahan yang ada, agar akibatnya tidak berlanjut dan memberi beban yang makin berat. Untuk itu RSUD Mgr.Gabriel Manek SVD Atambua menjadi lokasi penelitian yang peneliti gunakan selama 2 Minggu terhitung mulai tanggal 21 Januari2019 sampai tanggal 04 Februari 2019.

\section{b. Karakteristik Responden}

Karakteristik responden dalam penelitian ini sebanyak 177 responden. Peneliti membagikan kuesioner sebanyak 177 kuesioner, dan yang mengembalikan sebanyak 177 kuesioner juga. Dari 177 kuesioner tersebut 7 responden dinyatakan gugur karena tidak lengkap. Untuk menggambarkan secara rinci karakteristik responden dalam penelitian ini dapat diuraikan sebagai berikut yaitu berupa gambaran umum frekuensi dari jenis kelamin, umur, pendidikan, pekerjaan. Berikut gambaran umum berdasarkan distribusi frekuensi jenis kelamin sesuai dengan tabel dibawah ini :

\section{Tabel 1}

Distribusi frekuensi berdasarkan jenis kelamin responden ( $N: 170$ )

\begin{tabular}{|l|l|l|l|}
\hline No & $\begin{array}{l}\text { Jenis } \\
\text { kelamin }\end{array}$ & Frekuensi & $\begin{array}{l}\text { Persentase } \\
(\mathbf{\%})\end{array}$ \\
\hline 1 & Laki - laki & 73 & 42,94 \\
\hline 2 & Perempuan & 97 & 57,06 \\
\hline & Total & $\mathbf{1 7 0}$ & $\mathbf{1 0 0}$ \\
\hline
\end{tabular}

Sumber : Data Primer ( 2019 ).

Berdasarkan tabel 1 diatas dapat diketahui bahwa distribusi frekuensi responden sesuai dengan jenis kelamin adalah laki - laki 42,94 $\%$ dan perempuan $57,06 \%$.
Tabel 2

Distribusi frekueensi berdasarkan umur responen ( $N: 170)$

\begin{tabular}{|l|l|l|l|}
\hline No & Umur & Frekuensi & $\begin{array}{l}\text { Persentase } \\
(\mathbf{\%})\end{array}$ \\
\hline 1 & $12-$ & 17 & 10 \\
\hline 2 & $18-$ & 130 & 76,47 \\
& 40 & & \\
\hline 3 & $41-$ & 20 & 11,77 \\
& 65 & & 1,76 \\
\hline 4 & $\geq 66$ & 3 & $\mathbf{1 0 0}$ \\
\hline & Total & $\mathbf{1 7 0}$ & \\
\hline
\end{tabular}

Sumber : Data Primer ( 2019 ).

Berdasarkan tabel 2 diatas dapat diketahui bahwa kategori responden sesuai umur adalah kategori umur 12 - 17 tahun $10 \%$, umur $18-$ 40 tahun $76,47 \%$, umur $41-65$ tahun 11,77 $\%$, umur lebih dari 60 tahun $1,76 \%$.

Tabel 3

Distribusi frekuensi berdasarkan pendidikanresponden ( $N: 170$ )

\begin{tabular}{|l|l|l|l|}
\hline No & Pendidikan & Frekuensi & Persentase ( \% ) \\
\hline 1 & SD & 21 & 12,35 \\
\hline 2 & SLTP & 32 & 18,82 \\
\hline 3 & SLTA & 80 & 47,06 \\
\hline 4 & DIPLOMA & 19 & 11,18 \\
\hline 5 & S1 & 18 & 10,59 \\
\hline & TOTAL & $\mathbf{1 7 0}$ & $\mathbf{1 0 0}$ \\
\hline
\end{tabular}

Sumber : Data Primer ( 2019 ).

Berdasarkan tabel 3 diatas dapat diketahui bahwa distribusi frekuensi responden sesuai dengan pendidikan adalah SD 12,35\%, SLTP $18,82 \%$, SLTA $47,06 \%$, DIPLOMA $11,18 \%$, dan S1 10,59\%.

Tabel 4

Distribusi frekuensi berdasarkan pekerjaan responden ( $N: 170)$

\begin{tabular}{|l|l|l|l|}
\hline No & Pekerjaan & Frekuensi & Persentase (\% ) \\
\hline 1 & Swasta & 78 & 45,89 \\
\hline 2 & IRT & 10 & 5,89 \\
\hline 3 & TB & 40 & 23,53 \\
\hline 4 & PNS & 13 & 7,64 \\
\hline 5 & Pelajar & 24 & 14,11 \\
\hline 6 & Mahasiswa & 5 & 2,94 \\
\hline & Total & $\mathbf{1 7 0}$ & $\mathbf{1 0 0}$ \\
\hline
\end{tabular}

Sumber: Data Primer ( 2019 )

Berdasarkan tabel 4 diatas dapat diketahui bahwa distribusi frekuensi responden sesuai dengan pekerjaan adalah swasta 45,89\%, Ibu Rumah Tangga ( IRT ) 5,89\%, tidak bekerja ( TB ) $23,53 \%$, Pegawai Negri Sipil ( PNS ) 
7,64 \%, Pelajar 14,11\%, dan Mahasiswa $2,94 \%$.

Tabel 5

Distrbusi frekuensi persepsi masyarakat terhadap ODHA ( $N: 170$ )

\begin{tabular}{|l|l|l|l|}
\hline No & Kategori & Frekuensi & Persentase ( \% ) \\
\hline 1 & YA & 83 & 48,82 \\
\hline 2 & TIDAK & 87 & 51,18 \\
\hline & Total & $\mathbf{1 7 0}$ & $\mathbf{1 0 0}$ \\
\hline
\end{tabular}

Sumber : Data Primer ( 2019 ).

Berdasarkan tabel 5 diatas dapat diketahui bahwa terdapat 48,82\% masyarakat yang memberikan stigma negatif kepada ODHA dan terdapat 51,18 \% tidak memberikan stigma kepada ODHA.

\section{PEMBAHASAN}

\section{a. Distribusi Responden Menurut Jenis Kelamin.}

Berdasarkan peneliti terdahulu Anisa Fitriana Damalita , 2014 responden laki laki cenderung memiliki stigma dengan dominasi stigma lebih tinggi, dibanding dengan perempuan cenderung memiliki stigma dengan dominasi lebih rendah.

Sesuai dengan teori yang menyebutkan bahwa stigma yang terkait dengan jenis kelamin dapat mempengaruhi keadaan yang menyebabkan ketidakadilan sosial dan orientasi seksual yang sudah ada sebelumnya ( Parker, 2003 dan Sumatjono, 2000) dalam Monika Arum Mawarni, 2017. Sedangkan menurut Sosodono dkk, (2009 ) dalam Anisa Fitriana Damalita, 2014 mengatakan bahwa laki - laki mempunyai resiko berstigma jika dibandingkan dengan perempuan.

Berdasarkan hasil penelitian peneliti yang ada yaitu frekuensi berjenis kelamin laki - laki 73 persentasenya 42,94 \%, sertaberjenis kelamin perempuan frekuensi 97 persentasenya 57,06\% lebih tinggi. Sesuai dengan distribusi frekuensi dari 97 yang perempuan ada sebanyak 48 yang memberi stigma bagi ODHA dan sebanyak 49 tidak memberi stigma kepada ODHA. Oleh karena itu, peneliti berpendapat bahwa persentase responden berjenis kelamin perempuan lebih banyak dibandingkan laki - laki, karena umumnya yang berjenis kelamin laki - laki pergi bekerja, sedangkan yang perempuan lebih banyak dirumah dan mengurus keluarga. Penelitian ini hampir sejalan dengan penelitian dari Berek, et al (2018) yang menemukan bahwa terdapat hubungan yang bermakna antara jenis kelamin dengan tingkat pengetahuan remaja tentang HIV/AIDS dengan $\mathrm{p}=0,010$ pada alfa 0,05 .

\section{b. Distribusi Responden berdasarkan Umur.}

Berdasarkan Jurnal ( KESMA ) Volume 13 dalam Ni,mal Baroya, 2017, mengatakan bahwa usia lebih muda mempunyai kemungkinan bersikap menstigma ODHA dua kali lebih besar daripada yang berusia lebih tua.

Menurut Suganda, 1997 mengatakan umur secara alamiah mempunyai pengaruh terhadap perilaku seseorang. Bertambahnya umur seseorang mempengaruhi proses terbentuknya motivasi sehingga faktor umur diperkirakan berpengaruh terhadap perilaku seseorang.Dan menurut Hutapea, 2011 mengatakan persepsi yang salah terhadap HIV / AIDS menjadi penyebab remaja takut untuk berinteraksi langsung dengan ODHA sehingga remaja memiliki stigma terhadap ODHA.

Berdasarkan hasil penelitian peneliti, sesuai dengan distribusi frekuensi umur yaitu, umur 18 - 40 ada 130 responden dengan persentasenya 76,47 \% lebih tinggi. Dan dari frekuensi 130, ada 57 yang memberi stigma kepada ODHA dan 73 tidak memberi stigma kepada ODHA. Secara opini bahwa pada usia ini seseorang mampu menerima informasi dengan mudah dan memiliki kematangan dalam berpikir dan dapat memberikan persepsi sendiri. 


\section{c. Distribusi Responden berdasarkan Pendidikan.}

Menurut Bradley ( 2009 ) dalam penelitian yang dilakukan Tri Paryati didapatkan bahwa pengetahuan tentang HIV / AIDS sangat mempengaruhi bagaimana individu tersebut bersikap terhadap penderita HIV / AIDS.Sedangkan menurut penelitian Mahendra at al, ( 2007 ) dan penelitian Pratikno, (2008) dalam Tri.,dkk mengatakan bahwa terbukti adanya stigma dan diskriminasi terhadap ODHA dipengaruhi oleh tingkat pengetahuan.

Menurut Soedarjatmika (2008), mengatakan bahwa pengetahuan berpengaruh terhadap stigma diakibatkan oleh kurangnya pemahaman terhadap penyakit tersebut. Dan menurut Notoadmojo, (2003 ) mengatakan bahwa fungsi dari pengetahuan adalah mendorong individu untuk mengerti denga pengalaman- pengalamannya untuk memperoleh pengetahuan.

Sesuai hasil penelitian peneliti,dilihat dari distribusi berdasarkan pendidikan maka SLTA persentase $47,06 \%$ lebih tinggi dengan frekuensi 80 responden. Dari 80 responden dengan persentase pendidikan SLTA lebih tinggi, ada 41 responden yang memberi stigma kepada ODHA dan 39 responden tidak memberi stigma kepada ODHA.Sesuai opini bahwa pada zaman dahulu pendidikan tidak terlalu penting bagi orang tua dan orang tua tidak memberikan ijin bagi anak untuk bersekolah jauh dari orang tua. Oleh karena itu pendidikan yang rendah, sangat berpengaruh terhadap pola pikir seseorang dan pemahaman orang tersebut. Dan dengan pengetahuan yang kurang serta tidak terpaparnya informasi yang benar, membuat pemahaman serta cara pandang yang salahterhadap munculnya suatu masalah baru dalam kehidupan bermasyarakat sehingga dapat merubah perilaku orang tersebut dalam bersikap.

\section{d. Distribusi Responden Berdasarkan Pekerjaan.}

Berdasarkan peneliti terdahulu Febrianti, 2017, mengatakan status ekonomi keluarga yang rendah berpengaruh erhadap stigma berat pada ODHA, artinya status ekonomi keluarga rendah akan mempunyai resiko dua kali untuk memiliki stigma terhadap ODHA.
Menurut Soekanto, 2004 mengatakan interaksi sosial merupakan hubungan hubungan sosial yang dinamis yang menyangkut hubungan antara orang - orang perorangan, antara kelompok - kelompok manusia. Interaksi tidak akan tercipta dengan hanya bertemunya orang perorangan secara badaniah belaka, melainkan baru akan terjadi apabila orang - orang perorangan atau kelompok - kelompok manusia bekerja sama, saling berbicara dan seterusnya,untuk mencapai suatu tujuan bersama, mengadakan persaingan, pertikaian, dan lain sebagainya.

Sesuai hasil penelitian peneliti,distribusi frekuensi berdasarkan pekerjaan, maka pekerjaan swasta persentasenya 45,89 \% lebih tinggi dengan frekuensi 78 responden. Dan dari 78 responden tersebut ada 31 responden yang memberi stigma kepada ODHA dan 47 responden tidak memberi stigma kepada ODHA.dan sesuai opini bahwa kehidupan masyarakat selama ini adalah berpenghasilan dari bekerja sebagai pekerja swasta.

\section{KESIMPULAN.}

Gambaran persepsi masyarakat tentang stigmatisasibagi ODHA di RSUD Mgr Gabriel Manek SVD, Atambua ditemukan $51,18 \%$ tidak memberikan stigmatisasi bagi ODHA, walaupun masih terdapat 48,82\% yang memberikan stigma negatif kepada ODHA. Disarankan kepada institusi pendidikan agar dapat menyediakan referensi yang terbaru mengenai hal - hal yang berkaitan dengan penyakit HIV / AIDS.

\section{KEPUSTAKAAN}

Adhi Djuanda. 2005. Ilmu Penyakit Kulit dan Kelamin. Jakarta: Balai Penerbit FKUI.

Aziz Alimul Hidayat. 2007. Riset Keperawatan dan Teknik Penulisan IlmiahJakarta: Salemba Medika.

Berek, P. A. L., Be, M. F., Rua, Y. M., \& Anugrahini, C. (2018). Hubungan Jenis Kelamin dan Umur Dengan Tingkat Pengetahuan Remaja Tentang HIV/AIDS di SMAN 3 Atambua, 
Nusa Tenggara Timur, 1-13.

Brunner \& Suddarth. 2014. Keperawatan Medikal Bedah. Jakarta : Buku Kedokteran EGC.

Christanto. 2014. Kapita Selekta Kedokteran. Jakarta : Media Aesculapius.

Clevo Rendy. 2012. Asuhan Keperawatan Medikal Bedah dan Penyakit Dalam.Yogyakarta : Nuha Medika. Jurnal promosi - promosi kesehatan Indonesia, Vol.12 / No.1, 2017.

Fauk, N. K., Sukmawati, A. S., Berek, P.

A. L., Ernawati, Kristanti, E., Wardojo, S. S. I., ... Mwanri, L. (2018). Barriers to HIV testing among male clients of female sex workers in Indonesia. International Journal for Equity in Health, 17(1), 1-10. http://doi.org/10.1186/s12939018-0782-4

Notoadmojo, S, 2009. Pendidikan dan Promosi Kesehatan. Jakarta : Rineka Cipta.

Nursalam. 2007. Asuhan Keperawatan Pada Pasien Terinfeksi HIV/AIDS.Jakarta: Salemba Medika.

Soekidjo Notoatmodjo. 2005. Metodologi Penelitian Kesehatan. Jakarta :Rineka Cipta.

Widoyono. 2008. Penyakit Tropis Epidemiologi, Penularan, Pencegahan \& Pemberantasanya. Semarang : Erlangga.

Wilkins. 2006. Lecture Notes Penyakit Infeksi. Jakarta : Erlangga.

Yuli Peritiowati. 2014. Imunologi Diagnosis dan Teknik Biologi
Molekuler. Yogyakarta : Nuha Medika. 